\title{
3D modeling system of seismoacoustic monitoring results at the Nikolaevskoye field
}

\author{
Mikhail Lomov ${ }^{1 *}$ \\ ${ }^{1}$ Mining Institute FEB RAS, 51 Turgenev st., Khabarovsk, 680000, Russia
}

\begin{abstract}
The complexity of solving the problem of preventing natural and man-made disasters during intensive nature management is associated with the multifactorial nature of the conditions and causes of catastrophic events, significant variations in the properties and state of geospheres, and the lack of reliable criteria and precursors of dangerous dynamic phenomena.

The modern scientific approach to solving this problem consists in modeling processes that allow to adequately describe the state of changing natural and technical systems with subsequent verification of the results of theoretical research by instrumental methods. An even greater effect is brought by the combined use of natural and theoretical methods, united by a common ideology and maximally adapted to the conditions of the problem being solved, providing continuous multivariate monitoring of geophysical fields and processes in the geospheres.

In this regard, it seems very urgent to set up research work aimed at the development of scientific and methodological foundations and technical means for assessing and monitoring hazardous geomechanical processes to reduce the risk of man-made disasters during the development of mineral deposits.
\end{abstract}

\section{Introduction}

The complexity of solving the problem of preventing natural and man-made disasters during intensive nature management is associated with the multifactorial nature of the conditions and causes of catastrophic events, significant variations in the properties and state of geospheres, and the lack of reliable criteria and precursors of dangerous dynamic phenomena.

The modern scientific approach to solving this problem consists in modeling processes that allow to adequately describe the state of changing natural and technical systems with subsequent verification of the results of theoretical research by instrumental methods. An even greater effect is brought by the combined use of natural and theoretical methods, united by a common ideology and maximally adapted to the conditions of the problem being solved, providing continuous multivariate monitoring of geophysical fields and processes in the geospheres [1-4].

\footnotetext{
*Main author:9241515400@mail.ru
} 
In turn, the study of the properties and state of natural and technical systems requires interdisciplinary research, implying the processing and joint analysis of various data, as well as work with instrumental observation networks, measuring systems, etc. This requires the development of effective algorithms, technologies and high-performance computer systems for working with heterogeneous sets of scientific data, which should provide a comprehensive solution to the problems of collecting, integrating and processing large amounts of information [5].

In this regard, it seems very urgent to set up research work aimed at the development of scientific and methodological foundations and technical means for assessing and monitoring hazardous geomechanical processes to reduce the risk of man-made disasters during the development of mineral deposits [6].

\section{3D modeling system}

At this time, specialized software systems present the results of seismoacoustic monitoring in tabular form or graphically (flat maps and full 3D models).

As the experience of mining enterprises shows, preference is given to systems with graphical presentation of results.

An example of such systems is GCSVisualization software (Fig. 1).

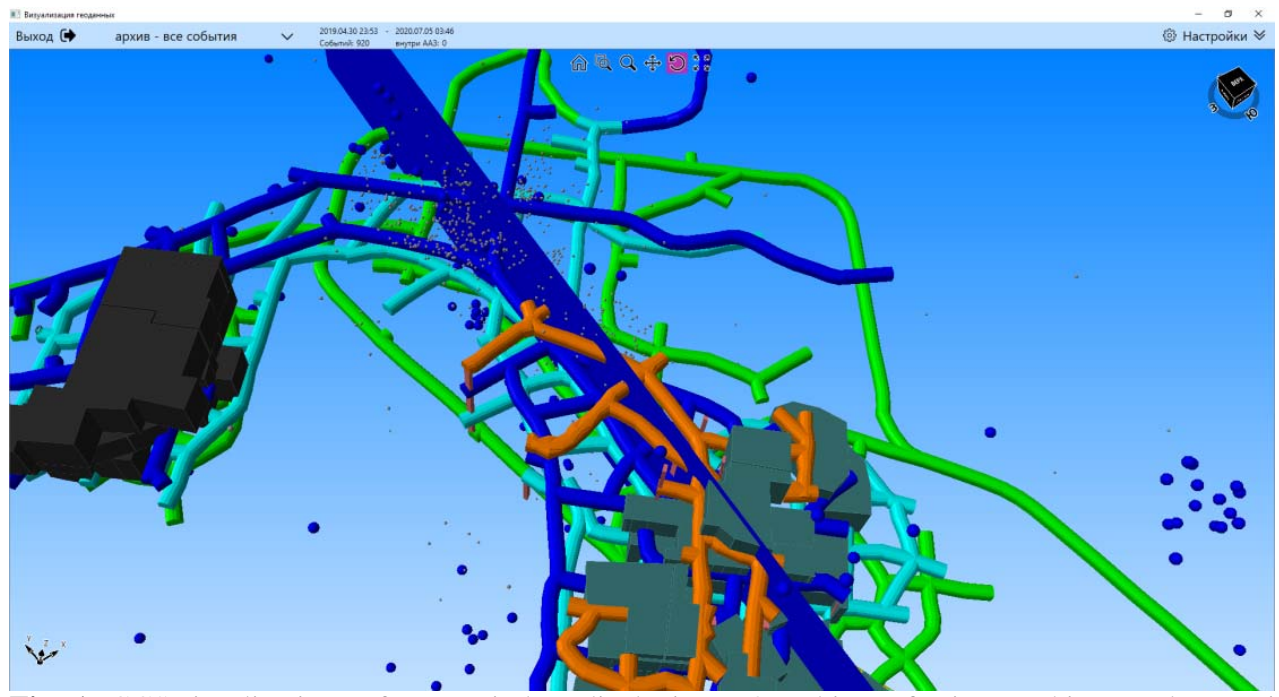

Fig. 1. GCSVisualization software window displaying a 3D object of mine workings and acoustic events at the Nikolaevskoye field

A feature of this program, developed at the Institute of Mining of the FEB RAS, is the display on the monitor of a 3D object of underground mine workings, created in the *.dwg or *.dxf format, and the sources of seismoacoustic events recorded by automated rock pressure monitoring system (ARPMS) Prognoz-ADS (Fig. 3). The color highlights the contours of acoustically active zones (AAZ) against the background of other AE events [7].

The software in real time accesses the ARPMS database on the operator's PC, from where the actual data (processed by the operator) is downloaded: well coordinates, seismicacoustic events, AAZ epicenters and their geometric parameters. A three-dimensional model of a mine is downloaded from a *.dwg or *.dxf file, created in the graphic editors AutoCAD, MineFrame, Micromine, Datamine, examples of which are shown in Figures 1,2 . 


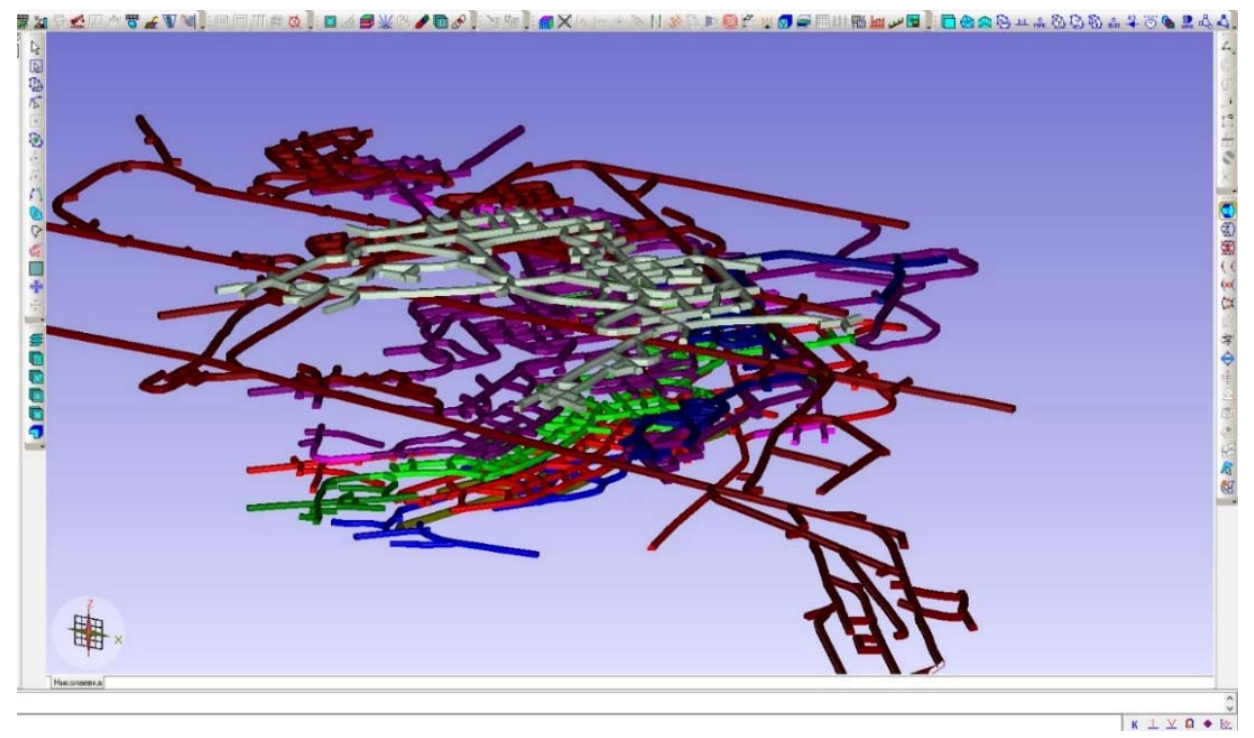

Fig. 2. 3D model of the Nikolaevskoye field

The main functions of GCSVisualization software:

1. Displaying in real time the location of sources of seismoacoustic events relative to underground mine workings;

2. Displaying the development process of acoustically active zones and their positioning relative to mine workings and structures;

3. Notification of large recorded seismoacoustic events;

4. Displaying the results in the main window in the form of graphs of changes in the parameters of acoustically active zones (a complex indicator of rock burst hazard, migration rate, total energy, etc.). During the demonstration, it is possible to rotate and detail a 3D object. When you hover the cursor over a source, information about the recording time, location and energy is displayed. Also, the screen displays information on AAZ, showing the values of the complex indicator $K_{u d}$ for the selected area, as well as other indicators of acoustic activity (total energy, quantity, coordinate of the hypocenter, etc.) [8].

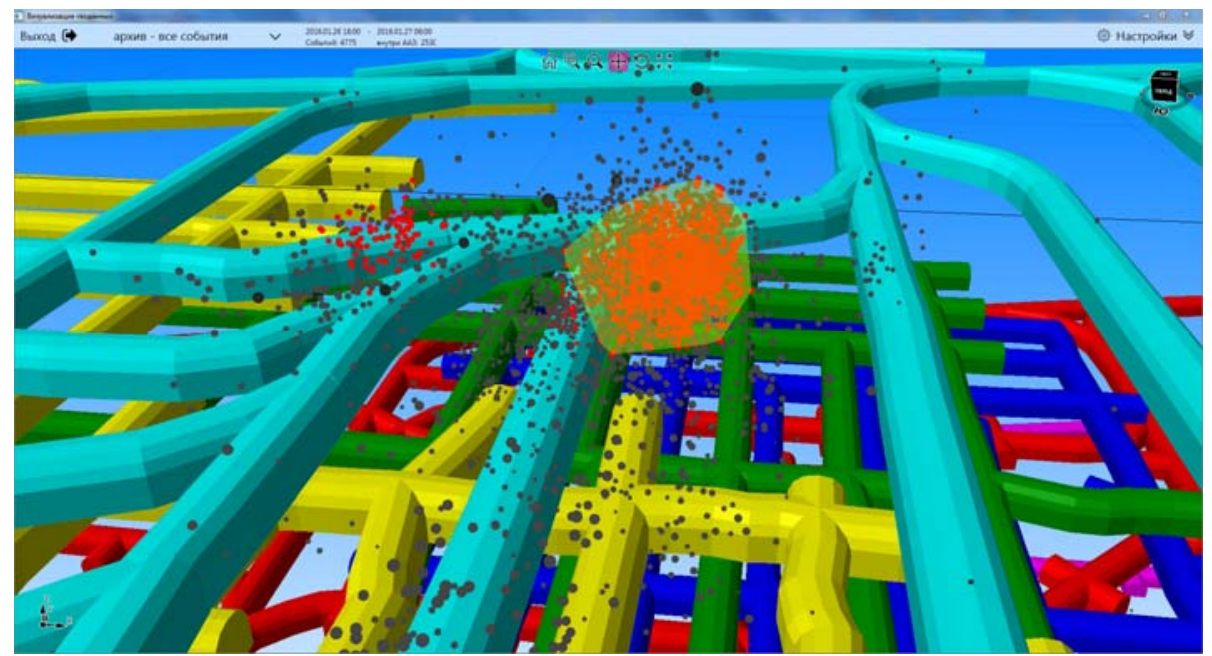

Fig. 3. GCSVisualization software window with monitoring results (visualization of a large AAZ recorded before a shock 
The development of GCSVisualization software will not end with 3D visualization. At the present time, the employees of the Institute of Mining of the FEB RAS are introducing methods for displaying information on the stress state of the rock mass on flat maps.

\section{Conclusion}

This method of monitoring the dynamic characteristics of seismoacoustic transducers using visualization of acoustic events differs from the known ones as it uses direct measurements of the studied characteristics. In this regard, it can be assumed that the measurement errors will be less, and the reliability will be higher, thereby preventing as many emergencies as possible at mining enterprises. The advantages of the method can also be attributed to the reduction of the influence of the human factor.

\section{References}

1. I.M. Petukhov, I.M. Batugina, Geodynamics of mineral resources (Moscow: Nedra, 1996)

2. V.I. Usikov, Pacific Geology, 6, 14 (2011)

3. A.V. Konstantinov, A.V. Gladyr, M.A. Lomov, Problems of subsoil use, 2 (21), 43 (2019)

4. A.V. Gladyr, M.I. Rasskazov, A.A. Tereshkin, A.V. Konstantinov, Fundamental and applied issues of mining sciences, 6-1, 78 (2019)

5. N.N. Melnikov, A.I. Kalashnik, N.A. Kalashnik, D.V. Zaporozhets, Physical and technical problems of mining, 4, 3 (2018)

6. A.N. Shabarov, S.V. Tsirel, K.V. Morozov, I.Yu. Rasskazov, Mining Journal, 9, 59 (2017)

7. A.V. Gladyr, G.A. Kursakin, M.I. Rasskazov, A.V. Konstantinov, Mining information and analytical journal, 8, 21 (2019)

8. I.Yu. Rasskazov, A.Yu. Iskra, V.A. Lugovoi, I.A. Barashikov, Civil Security Technologies, 7-3 (25), 92 (2010) 